\title{
EX VIVO LIPOSOME-MEDIATED GENE TRANSFER TO LUNG ISOGRAFTS
}

Carlos H. R. Boasquevisque, $\mathrm{MD}^{\mathrm{a}}$ Bassem N. Mora, MD ${ }^{a}$

Matthew Bernstein, $\mathrm{BS}^{\mathrm{b}}$

William O. Osburn, BA ${ }^{\mathrm{c}}$

Jennifer Nietupski, $\mathrm{BSc}^{\mathrm{c}}$

Ronald K. Scheule, $\mathrm{PhD}^{\mathrm{c}}$

Joel D. Cooper, $\mathrm{MD}^{\mathrm{a}}$

Mitchell Botney, $\mathrm{MD}^{\mathrm{b}}$

G. Alexander Patterson, $\mathrm{MD}^{\mathrm{a}}$
Objective: Gene therapy is a promising strategy to modify ischemiareperfusion injury and rejection after transplantation. We evaluated variables that may affect ex vivo gene transfer to rat lung isografts. Methods: Left lungs were harvested and perfused via the pulmonary vein with chloramphenicol acetyltransferase complementary deoxyribonucleic acid complexed with cationic liposomes. Several variables were examined: (1) Influence of temperature: In group I $(n=4)$, grafts were stored for 4 hours at $23^{\circ} \mathrm{C}$ and transplanted. Chloramphenicol acetyltransferase activity was assessed on postoperative day 2 . In groups II and III $(n=4)$, grafts were stored at $10^{\circ}$ and $4^{\circ} \mathrm{C}$, respectively. Arterial oxygen tension and inflammatory infiltrate were also determined. (2) Influence of storage time: Grafts were preserved at $10^{\circ} \mathrm{C}$ for $1,2,3,4(n=4)$, and 10 hours $(n=5)$. Chloramphenicol acetyltransferase activity was assessed on postoperative day 2. (3) Rapidity and duration of transgene expression: Grafts were preserved at $10^{\circ} \mathrm{C}$ for 1 hour and then transplanted. Chloramphenicol acetyltransferase activity was assessed 2, 4, 6, 12, and 24 hours and 2, 7, 14, 21, and 28 days after implantation. Results: Chloramphenicol acetyltransferase expression was apparently less in lungs transfected at $4^{\circ} \mathrm{C}$ than in those transfected at $10^{\circ}$ and $23^{\circ} \mathrm{C}$. Storage for 1 hour at $10^{\circ} \mathrm{C}$ was sufficient to yield significant expression. Increasing the exposure time to 10 hours did not increase toxicity. There were no differences in arterial oxygen tension between transfected and nontransfected lungs. Chloramphenicol acetyltransferase expression was detected for at least 28 days. Conclusion: Ex vivo liposome-mediated transfection of lung isografts can be achieved after a short time of cold storage, with minimal toxicity. (J Thorac Cardiovasc Surg 1998;115:38-44)
$T^{\mathrm{h}}$ he progress of techniques to introduce exogenous deoxyribonucleic acid (DNA) into mammalian somatic cells has opened up the possibility of treating inherited and acquired diseases at the genetic level. In lung transplantation, gene therapy may prove useful to prevent or attenuate complications

From the Divisions of Cardiothoracic Surgery ${ }^{\mathrm{a}}$ and Respiratory and Critical Care Medicine, ${ }^{\mathrm{b}}$ Departments of Surgery and Medicine, Washington University School of Medicine, St. Louis, Mo., and Genzyme Corporation, ${ }^{\mathrm{c}}$ Framingham, Mass.

Supported by the National Institutes of Health grants 1 R01 HL-41281 and HL-29594 and Alan A. and Edith Wolff Charitable Trust.

Received for publication May 21, 1997; revisions requested July 15, 1997; revisions received Sept. 17, 1997; accepted for publication Sept. 18, 1997.

Address for reprints: G. Alexander Patterson, MD, 3108 Queeny Tower, One Barnes Hospital Plaza, St. Louis, MO 63110.

Copyright (c) 1998 by Mosby, Inc.

$0022-5223 / 98 \$ 5.00+0 \quad \mathbf{1 2 / 1 / 8 6 3 4 0}$ such as ischemia-reperfusion injury, rejection, and infection.

Gene delivery systems play a central role in gene therapy. Currently used replication-deficient viral vectors raise problems such as host immune-inflammatory responses and oncogenicity. ${ }^{1-4}$ Transgene expression is transient and, contrary to liposomal vectors, a second administration is not effective, because the newly transduced cells are destroyed by host immune responses. ${ }^{3}$ Furthermore, when an adenovirus vector is delivered to the pulmonary microvasculature, an unpredictable transduction pattern is observed. ${ }^{5,6} \mathrm{We}^{7}$ have previously reported the use of a liposomal vector to transfect lung grafts before harvest (in vivo donor transfection). With this vector, we observed consistent and homogeneous distribution of expression throughout the lung parenchyma. In addition, the observed toxicity was minimal and there was no impairment of subsequent graft function. However, in the in vivo approach, 


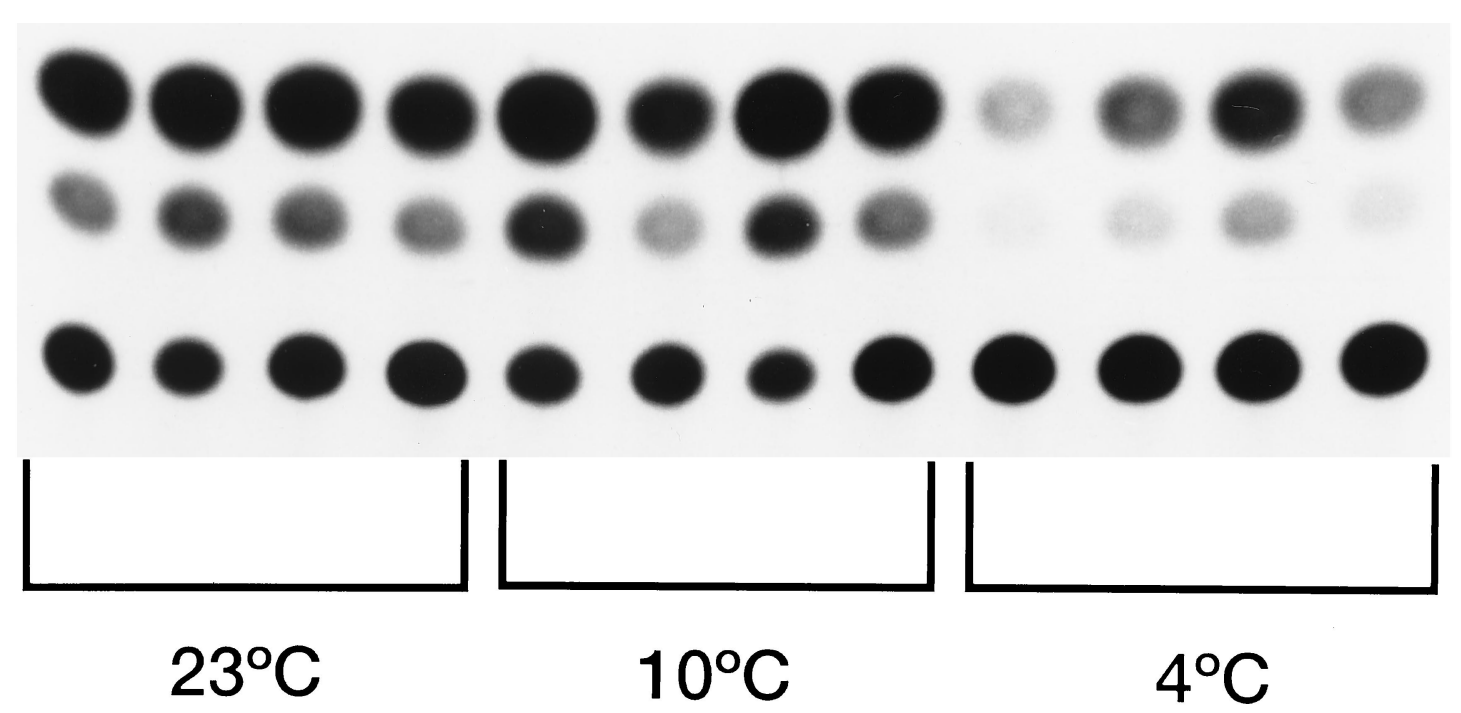

Fig. 1. CAT activity in lung grafts transfected ex vivo and stored for 4 hours at $23^{\circ}, 10^{\circ}$, and $4^{\circ} \mathrm{C}$. CAT activity in the transplanted left lungs was assessed on postoperative day 2. Each column represents one animal. The bottom row represents nonacetylated chloramphenicol, the middle row represents monoacetylated chloramphenicol, and the top row represents diacetylated chloramphenicol. The top two rows are observed only when CAT is present. CAT activity was present in both groups stored at low temperatures, although there was apparently less in the $4^{\circ} \mathrm{C}$ group than in the $10^{\circ} \mathrm{C}$ group.

transgene expression was not restricted to lungs, but was also observed in donor hearts. Whether this would pose a problem in the context of multiple cadaveric organ retrieval requires additional studies with functional genes. An ex vivo approach might circumvent this potential problem.

Recently, ex vivo liposome-mediated gene transfer to rabbit heart allografts has been reported. ${ }^{8}$ $\mathrm{We}^{7}$ have shown that this vector system is possible in the setting of lung transplantation, using a rat lung transplant model and the chloramphenicol acetyltransferase (CAT) reporter gene. In the current study, we specifically aimed to determine (1) the influence of graft storage temperature on transfection efficiency, (2) the influence of storage time on ex vivo transfection efficiency, (3) the rapidity and duration of transgene expression after graft implantation, (4) whether the ex vivo strategy yields transgene expression restricted to the lung grafts, and (5) whether transgene expression could occur during the preservation time.

\section{Materials and methods}

Plasmid expression vector. The plasmid pCF1-CAT (Genzyme Corporation, Framingham, Mass.) consists of the human cytomegalovirus immediate early gene promoter/enhancer, a hybrid intron, the CAT cDNA, the bovine growth hormone polyadenylation signal sequence, and a kanamycin resistance gene and was constructed as previously described. ${ }^{9}$

Preparation of cationic lipid:L-dioleoyl phosphatidylethanolamine (DOPE):DNA complexes. Lipid 67 (Genzyme Corporation) is an amphophile consisting of a hydrophobic lipid anchor (cholesterol) linked to a spermine head group in a T-shaped configuration. Lipid 67: DOPE, in a molar ratio of 1:2, was supplied as dried films and prepared as previously described. ${ }^{9}$ Before use, the films were hydrated with sterile water, treated in a vortex until opaque, incubated on ice for 10 minutes, and then treated in a vortex again for 2 minutes. Equal volumes of lipid 67:DOPE and CAT cDNA were mixed and incubated at room temperature for a minimum of 30 minutes. Final lipid and DNA concentration were $1 \mathrm{mmol} / \mathrm{L}$ and 4 mmol/L, respectively.

Animals. Inbred male Fischer rats weighing 270 to 300 gm (Charles River Laboratories, Wilmington, Mass.) were used in all experiments. Animals received humane care in compliance with the "Principles of Laboratory Animal Care" formulated by the National Society for Medical Research and the "Guide for the Care and Use of Laboratory Animals" prepared by the Institute of Laboratory Animal Resources and published by the National Institutes of Health (NIH Publication No. 85-23, revised 1985).

Rat lung transplantation. An orthotopic left lung rat transplant model was developed by means of a modification of the "cuff" technique. ${ }^{10}$ In brief, donor lungs were flushed through the main pulmonary artery with $20 \mathrm{ml}$ of normal saline solution at $20 \mathrm{~cm} \mathrm{H}_{2} \mathrm{O}$ of pressure. The heart-lung block was excised with the lungs inflated at 


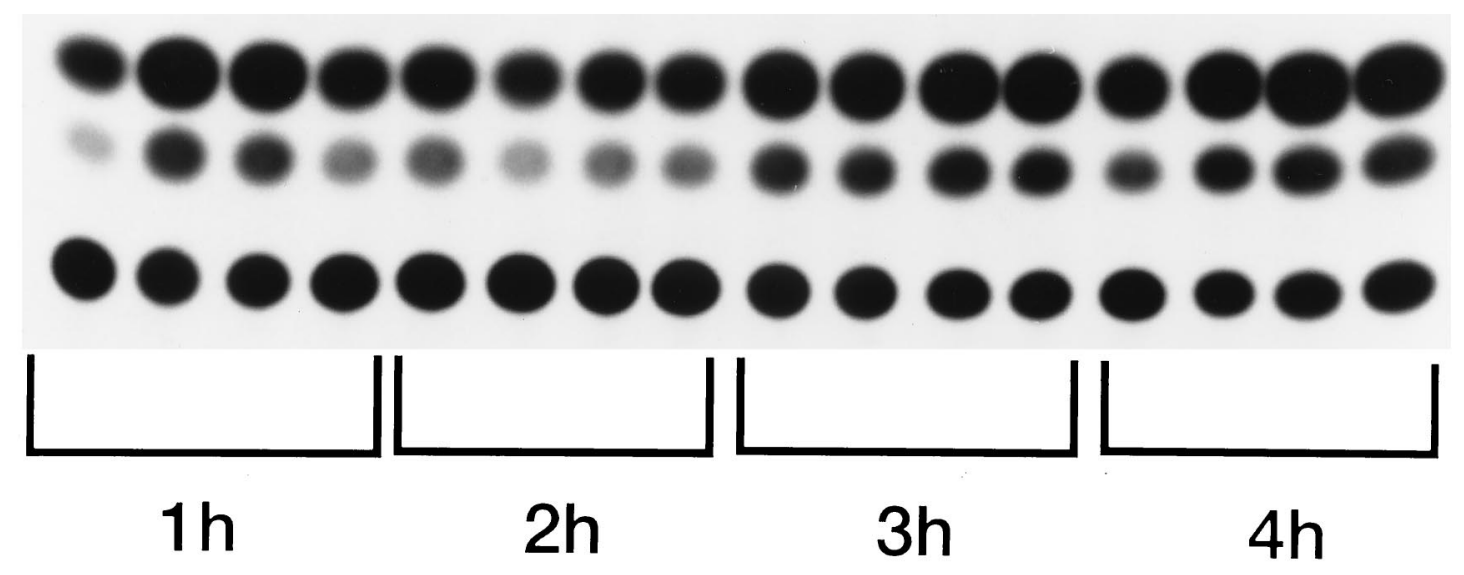

Fig. 2. CAT activity in lung grafts transfected ex vivo and stored at $10^{\circ} \mathrm{C}$ for 1 hour, 2 hours, 3 hours, and 4 hours. Storage times as short as 1 hour were sufficient to yield significant transgene expression.

end-tidal volume and the left pulmonary vein was cannulated with a silicone catheter inserted through the left atrial appendage. Lipid 67:DOPE:CAT was diluted in 10 $\mathrm{ml}$ of saline solution and infused retrogradely over 7 to 10 minutes at $20 \mathrm{~cm} \mathrm{H}_{2} \mathrm{O}$ pressure. The retrograde flush was used because it is extremely easy to cannulate the vein through the left atrial appendage and also because distribution of the preservation solution is better when it was perfused in a retrograde fashion. ${ }^{11}$ Subsequently, the left lung was dissected and 14-gauge cuffs were inserted into the left pulmonary artery, vein, and bronchus. The grafts were implanted with the use of a cuff technique for all anastomoses, and recipient animals were allowed to recover from anesthesia.

Experimental design

Influence of storage temperature on ex vivo transfection efficiency. Left lungs were harvested and divided into three groups ( $n=4$ per group). In group I, lipid 67: DOPE:CAT cDNA was diluted in $10 \mathrm{ml}$ of normal saline solution and infused retrogradely into the left lung. Grafts were stored at $23^{\circ} \mathrm{C}$ for 4 hours and then implanted. In groups II and III, grafts underwent the same procedure, but storage was at $10^{\circ}$ and $4^{\circ} \mathrm{C}$, respectively. On postoperative day 2, left lungs were harvested for CAT assay.

Influence of storage time on ex vivo transfection efficiency. Left lungs were harvested and divided into four groups ( $n=4$ per group). In group I, lipid 67:DOPE:CAT cDNA (0.25:0.50:1.0 mol) was infused retrogradely through the pulmonary vein. Grafts were stored at $10^{\circ} \mathrm{C}$ for 1 hour and then transplanted. Recipients were killed on postoperative day 2 and transplanted lungs were assessed for CAT activity. In groups II, III, and IV, lungs were stored for 2,3 , and 4 hours, respectively, and CAT activity in transplanted lungs was assessed on postoperative day 2 .

Rapidity of transgene expression. Left lungs were harvested and lipid 67:DOPE:CAT cDNA (0.25:0.50:1.0 mol) was infused retrogradely. Grafts were stored at $10^{\circ} \mathrm{C}$ for 1 hour and divided into six groups ( $n=4$ per group). In group I, grafts were frozen after the 1-hour storage period and assayed for CAT activity. In groups II, III, IV, V, and VI, lung grafts were transplanted and recipient animals were killed 2, 4, 6, 12, and 24 hours later and CAT activity was determined.

Duration of transgene expression. Lung grafts were infused retrogradely with lipid 67:DOPE:CAT cDNA (0.25: 0.50:1.0 mol), stored at $10^{\circ} \mathrm{C}$ for 1 hour, and then transplanted. Recipient animals were killed 2, 7, 14, 21, and 28 days after transplantation and CAT activity was assessed ( $n=4$ per group).

Extrapulmonary transgene expression. Extrapulmonary CAT activity was determined in recipient animals that received lungs transfected for 4 hours at $23^{\circ} \mathrm{C}$. Forty-four hours after transplantation, recipients were killed and lungs were flushed with normal saline solution. Transplanted left lungs, hearts, and livers were snap-frozen in liquid nitrogen and stored at $-80^{\circ} \mathrm{C}$ until assayed for CAT activity.

Transgene expression during the preservation time. To verify whether transgene expression could occur during the preservation time, before implantation, we infused ex vivo $660 \mu \mathrm{g}$ of CAT cDNA complexed to lipid 67 and diluted in $5 \mathrm{ml}$ of normal saline solution into the harvested left lung $(n=5)$. After 12 hours of exposure at $10^{\circ} \mathrm{C}$, the grafts were frozen and assessed for CAT activity.

CAT activity assay. Transgene expression was detected by a CAT activity assay by means of thin-layer chromatography as described elsewhere. ${ }^{7,12}$ The CAT enzyme catalyzes the transfer of one or two acetyl groups from acetyl coenzyme A to chloramphenicol, yielding monoacetylated and diacetylated forms of chloramphenicol, which by thin-layer chromatography are distinct from the nonacetylated chloramphenicol (Fig. 1). Eukaryotic cells contain no background of CAT activity, and therefore any activity detected in lung homogenates comes from the successfully transferred CAT gene.

Evaluation of pulmonary toxicity. The pulmonary toxicity of the liposome-plasmid complex was evaluated by assessing lung gas exchange and inflammatory infiltrates (hematoxylin and eosin staining). Additionally, in five animals, the lung grafts were infused with double the dose of liposome-DNA complexes previously used, preserved for 10 hours at $10^{\circ} \mathrm{C}$, and then transplanted. To serve as 


\section{Rapidity of Transgene Expression}
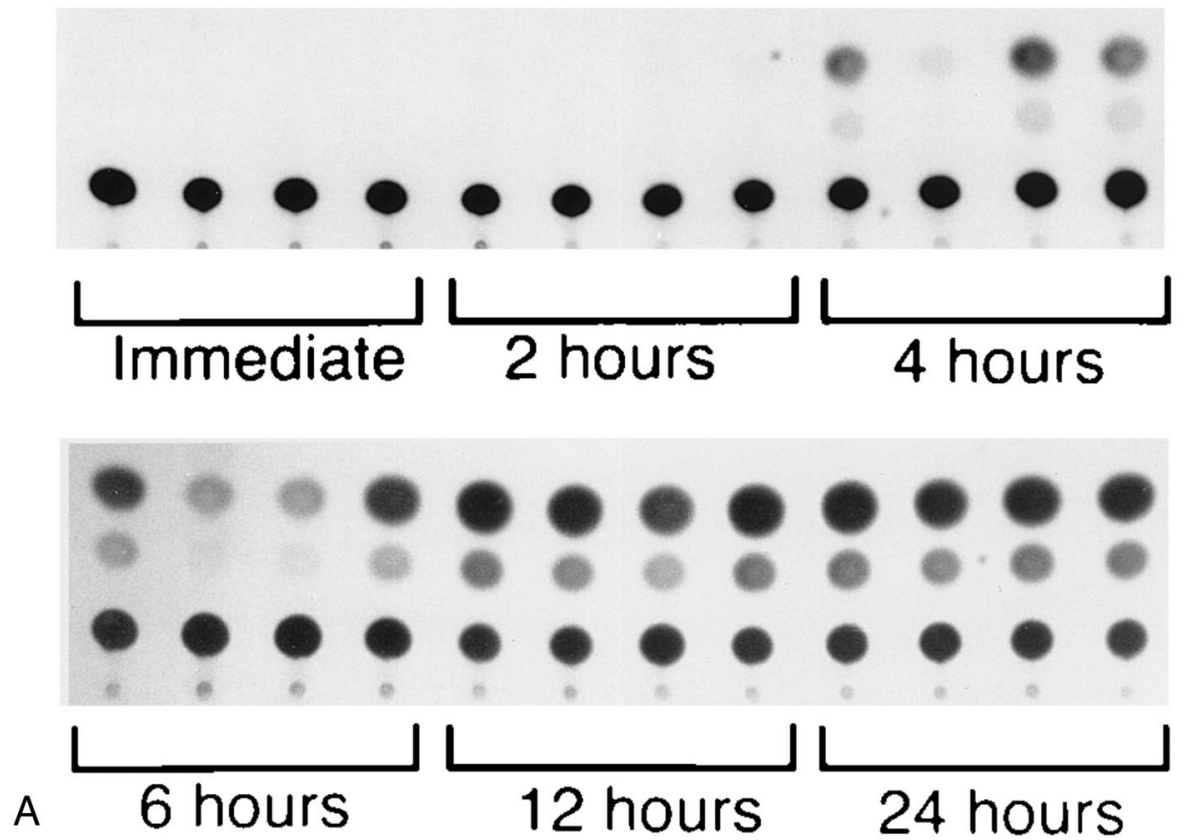

\section{Duration of Transgene Expression}
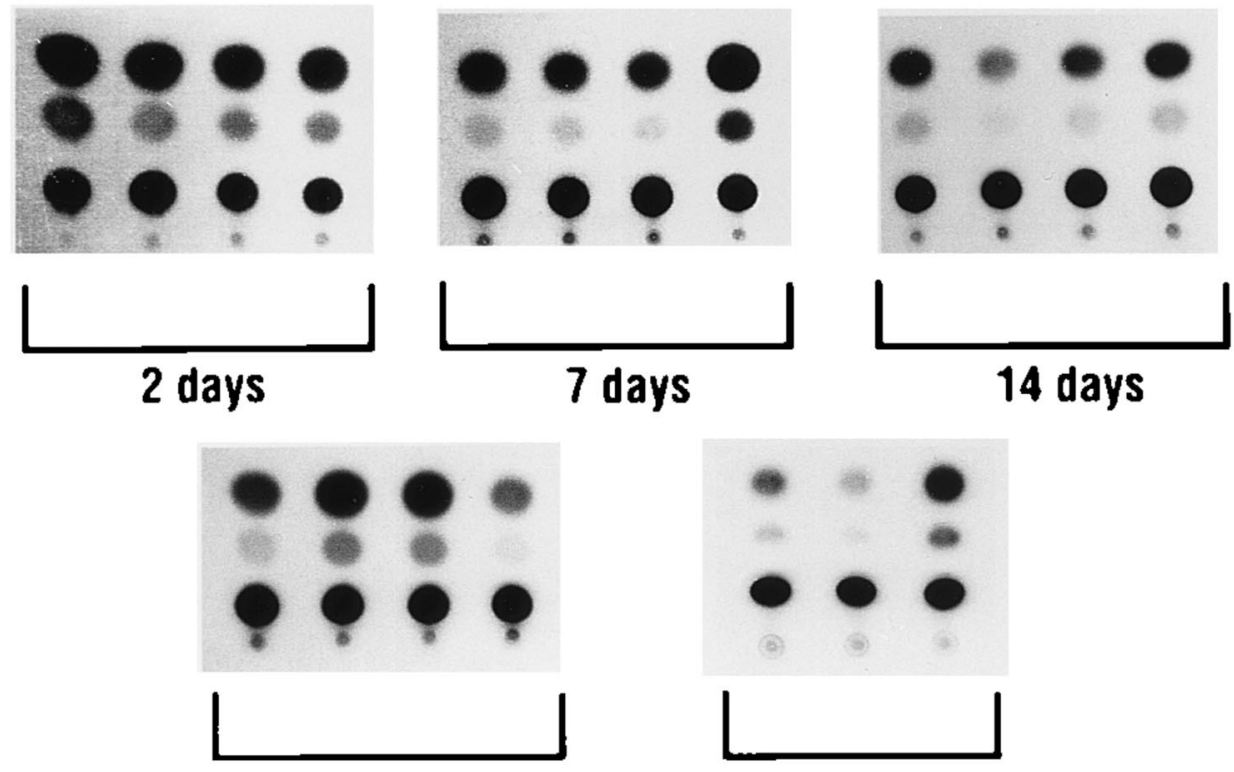

B

21 days

28 days

Fig. 3. Rapidity (A) and duration (B) of transgene expression in the ex vivo setting after storage at $10^{\circ} \mathrm{C}$ for 1 hour, transplantation, and assessment for CAT activity at different time points. Transgene expression became detectable 4 to 6 hours after implantation, and significant levels were observed at least for 28 days. Each column represents one animal. 


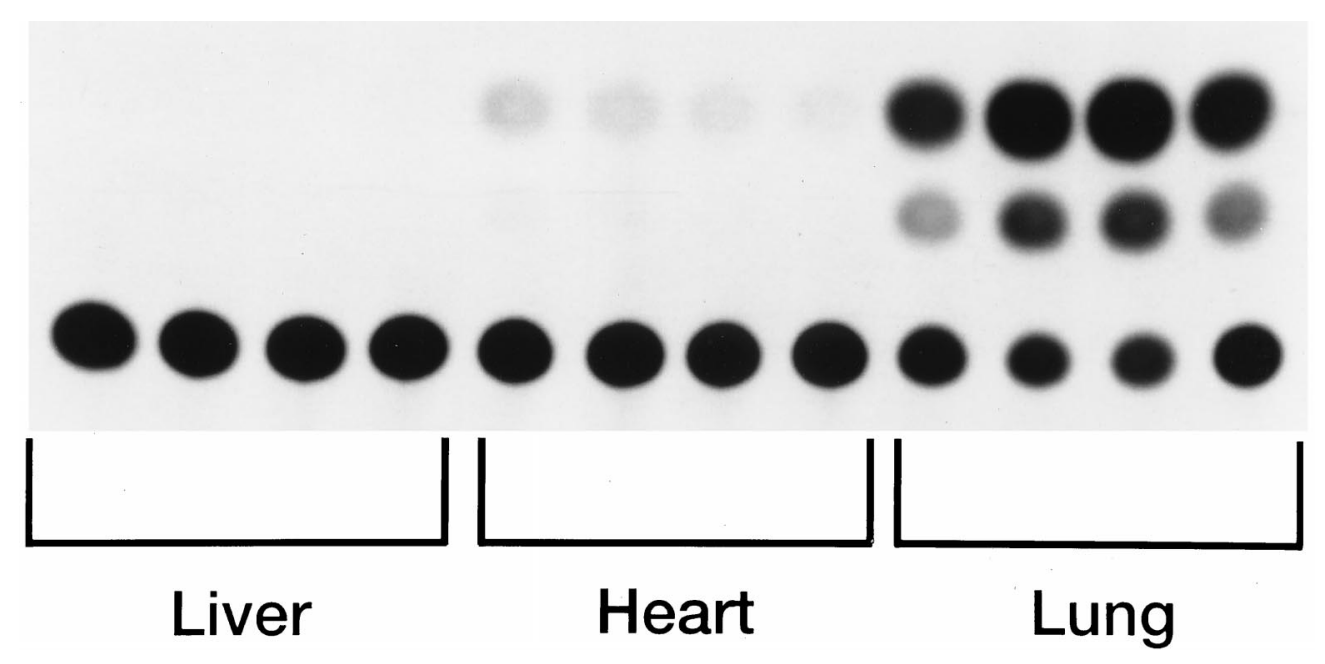

Fig. 4. Extrapulmonary transgene expression. Lungs were transfected ex vivo, stored for 4 hours at $23^{\circ} \mathrm{C}$, and transplanted. On postoperative day 2 organs were harvested and analyzed for CAT activity. Minimal levels of CAT activity were observed in recipient hearts. There was detectable CAT activity in recipient livers. Heart expression could be eliminated by rinsing the lung vasculature before implantation (data not shown).

controls, five animals underwent the same procedure but the grafts were not infused with liposome-CAT cDNA complexes. This was done to verify whether a longer exposure time to liposomes could affect the graft function.

Arterial oxygenation was determined as follows. In the transplant setting, rats were anesthetized with pentobarbital (50 mg/kg), systemically heparinized (1000 IU heparin per kilogram), and subjected to a median sternotomylaparotomy. The right pulmonary artery and right mainstem bronchus were clamped and the left lung was ventilated (inspired oxygen fraction, 1; tidal volume, $2 \mathrm{ml}$; respiratory rate, 80 breaths $/ \mathrm{min}$ ) and perfused for 5 minutes. An arterial blood sample was then obtained from the abdominal aorta and analyzed for oxygenation. In normal rats, arterial oxygenation was determined while both lungs were ventilated for at least 5 minutes with the use of the same parameters previously described.

Statistical analysis. Data were compared by $t$ test by means of the software Microsoft Excel for Windows 95, version 7.0 (Microsoft Corporation, Redmond, Wash.), when applicable. Data were expressed as mean \pm standard error, with a $p<0.05$ considered statistically significant.

\section{Results}

Eighty-two lung transplants were performed throughout this study with one operative death caused by a technical failure. Transgene expression was observed in all grafts transfected ex vivo.

Influence of storage temperature. Transgene expression was observed in all grafts transfected at $23^{\circ}$, $10^{\circ}$, and $4^{\circ} \mathrm{C}$. CAT activity was less in lungs stored at $4^{\circ} \mathrm{C}$ than in those stored at $23^{\circ}$ and $10^{\circ} \mathrm{C}$. Expression was roughly equivalent in lung grafts stored at $10^{\circ}$ and $23^{\circ} \mathrm{C}$ (Fig. 1).

Influence of storage time. Significant and essentially equivalent CAT activity was observed in grafts transfected ex vivo and stored at $10^{\circ} \mathrm{C}$ for 1 or 2 hours before transplantation (Fig. 2). Increasing the storage time to 3 or 4 hours led to a slight increase in transgene expression, as shown in Fig. 2.

Rapidity and duration of transgene expression. Transgene expression was negligible in lung grafts that were snap-frozen immediately after the 1-hour storage period and in lungs assessed 2 hours after transplantation. CAT activity reached significant levels 4 to 6 hours after reperfusion, peaked at 12 hours, and significant levels were maintained in most grafts for at least 28 days (Fig. 3, $A$ and $B$ ).

Transgene expression during the preservation time. No CAT activity was detected in any lung grafts after 12 hours of exposure to the liposomeCAT cDNA complexes.

Extrapulmonary transgene expression. CAT activity, albeit minimal, could be detected in recipient hearts. On the other hand, no CAT activity was detected in livers (Fig. 4). When grafts were flushed with normal saline solution before implantation to remove the lipid-DNA complex from the lung microvasculature, no CAT activity was detected in the recipient hearts. 
Pulmonary toxicity of lipid 67:DOPE:CAT. No significant difference in arterial oxygenation was observed in animals that received grafts transfected ex vivo for 4 hours at $10^{\circ} \mathrm{C}$ compared with normal controls $(546 \pm 17.6 \mathrm{~mm} \mathrm{Hg}$ vs $523.5 \pm 18.4 \mathrm{~mm} \mathrm{Hg}$ for transfected animals and normal controls, respectively; $n=5$ per group; $p=0.4, t$ test : two sample hours did not affect arterial oxygenation [529 \pm 31 $\mathrm{mm} \mathrm{Hg}$ vs $532 \pm 99 \mathrm{~mm} \mathrm{Hg}$ for grafts transfected ex vivo for 10 hours and transplanted and nontransfected assuming equal variances]). In addition, increasing the time of exposure to the liposome-DNA complexes to 10 grafts preserved at $10^{\circ} \mathrm{C}$ for 10 hours and transplanted, respectively, $p=0.97, t$ test : two sample assuming unequal variances). Hematoxylin and eosin staining demonstrated a minimal mononuclear cell infiltrate.

\section{Discussion}

$\mathrm{We}^{7}$ have recently reported our results with an in vivo liposome-mediated gene transfer approach, in which the donor was treated intravenously before harvest. The objective of that initial study was to achieve transgene expression at the time of harvest. ${ }^{7}$ In that setting, we demonstrated that in vivo liposome-mediated gene transfer to rat lung isografts was efficient, did not interfere with graft function, and transgene expression was present at the time of harvest when the liposome-DNA complex was injected at least 2 hours before harvest. Transgene expression was also high in donor hearts and minimally present in livers and kidneys. Thus complete target specificity was not achieved with the in vivo approach, which is important in the setting of multiple cadaveric organ retrieval.

The ex vivo approach should restrict transgene expression to the organ of interest. Surprisingly, when we transfected lung grafts ex vivo, transgene expression was also detected in recipient hearts, although this was minimal. Even when minimal transgene expression occurs, it is important to remember that this expression is transient and thus should not pose a problem. Moreover, other investigators have shown that liposomes are not toxic to hearts. ${ }^{13,14}$ This heart-based expression could be eliminated by flushing the grafts before implantation to remove the remaining liposome-DNA complexes from the pulmonary microvasculature.

In the present study, all lung grafts transfected ex vivo showed recombinant gene expression as demonstrated by the CAT assay. In this setting, significant transgene expression was observed for at least
28 days after infusion of the lipid-DNA complex. This result differs from that obtained in the in vivo setting, where transgene expression was minimal on day $21 .{ }^{7}$ We speculated that the ex vivo approach allows a more prolonged and undisturbed contact between the liposome-DNA complexes and the endothelium, contrary to the in vivo approach, where the blood flow could be a disturbing factor. This could account for a better transfection rate with the ex vivo approach and consequently a more prolonged transgene expression.

To be practical, the transfection procedure must not be a source of injury to the graft. Studies in healthy human volunteers have shown no acute adverse effects when liposomes were administered by aerosol inhalation. ${ }^{15}$ Canonico and associates ${ }^{16}$ have demonstrated in rabbits that weekly intravenous or aerosol delivery of cationic liposome-DNA complexes did not affect lung histology, mechanics, or oxygenation. In our present study, we observed minimal lung toxicity from the cationic lipid-DNA complexes. Graft function was not significantly affected, as demonstrated by normal arterial oxygenation and minimal host inflammatory response. This is contrary to what has been shown with viral vectors, which are capable of triggering a significant host immune-inflammatory response that hampers transgene expression and leads to low transduction efficiency if a second administration of the viral vector-DNA is required. Conversely, the liposomal vector has been demonstrated to allow sustained transgene expression when readministered, inasmuch as it does not activate the host immune system. ${ }^{9,16}$

Our study demonstrates that ex vivo liposomemediated gene transfer can occur under conditions that mimic those required clinically, such as cold storage for short periods of time. This is especially important in the setting of transplantation, because it avoids the paradox of increasing storage time and consequently ischemic time to allow gene transfer to occur. We have demonstrated that liposome-mediated graft transfection can occur with a storage time as short as 1 hour and results in CAT activity similar to that observed in lungs stored for 3 or 4 hours. Although the chromatographic method for CAT activity allows visual confirmation of the data, it is not accurate to quantify this activity because of its narrow linear range, which is a limitation of the method in this study.

Further, we observed that when the liposome-DNA complex remained in the pulmonary microvasculature 
for longer cold storage times (10 hours), no toxicity was observed, on the basis of arterial oxygenation measured when ventilating only the transplanted lung. One would expect that low temperature could affect gene transfer, because cellular metabolism is significantly decreased. Indeed, transgene expression appeared to be less in lungs transfected at $4^{\circ} \mathrm{C}$ when compared with those transfected at $10^{\circ} \mathrm{C}$. On the other hand, we cannot assure that this will correspond to a decrease in functional effect when a functional gene is used. This remains to be tested with a functional gene. Further, when we doubled the liposomeCAT cDNA concentration ( $660 \mu \mathrm{g}$ of DNA), we did not observe an increase in toxicity.

In the ex vivo setting, significant transgene expression was not observed until 4 to 6 hours after implantation. Although this timing of expression should not pose a problem when the clinical target is allograft rejection, it may not be the ideal situation for ischemia-reperfusion injury, where transgene expression at the time of implantation would be optimal.

In summary, we have determined the pattern of transgene expression in the setting of lung transplantation, using an ex vivo approach and a reporter gene (CAT) complexed to cationic lipids. Our study demonstrates that ex vivo gene transfer to lung isografts at low temperature yields consistent and reproducible transgene expression. In addition, it shows that transgene expression can be achieved with short storage times and that transfection does not interfere with subsequent graft function. Whether these levels of transgene expression are sufficient to produce beneficial effects in the graft will be determined in future studies in which functional genes are used.

\section{REFERENCES}

1. Vile RG, Russell SJ. Retroviruses as vectors. Br Med Bull 1995;51:12-30.

2. Wang Q, Finer MH. Second generation adenovirus vectors. Nature Med 1996;2:714-6.

3. Yang Y, Li Q, Ertl HC, Wilson JM. Cellular and humoral immune responses to viral antigens create barriers to lungdirected gene therapy with recombinant adenoviruses. J Virol 1995;69:2004-15.

4. Brody SL, Meltzger M, Danel C, Rosenfeld MA, Crystal RG. Acute responses of non-human primates to airway delivery of an adenovirus vector containing the human cystic fibrosis transmembrane conductance regulator cDNA. Hum Gene Ther 1994;5:821-36.

5. Chapelier A, Danel C, Mazmanian M, et al. Gene therapy in lung transplantation: feasibility of ex vivo adenovirus-mediated gene transfer to the graft. Hum Gene Ther 1996;7:1837-45.

6. Boasquevisque CHR, Mora BN, Schmid RA, et al. Ex vivo adenoviral-mediated gene transfer to lung isografts during cold preservation. Ann Thorac Surg 1997;63:1556-61.

7. Boasquevisque CHR, Lee TC, Mora BN, Peterson D, Osburn WO, Bernstein M, et al. Liposome-mediated gene transfer to lungs isografts. J Thorac Cardiovasc Surg 1997; 114:783-92.

8. Dalesandro J, Akimoto H, Gorman CM, McDonald TO, Thomas R. Gene therapy for donor hearts: ex vivo liposomemediated transfection. J Thorac Cardiovasc Surg 1996;111:41622.

9. Lee ER, Marshall J, Siegel CS, et al. Detailed analysis of structures and formulations of cationic lipids for efficient gene transfer to the lung. Hum Gene Ther 1996;7:1701-17.

10. Mizuta T, Kawaguchi AT, Nakahara K, Kawashima YL. Simplified rat lung transplantation using cuff technique. J Thorac Cardiovasc Surg 1989;97:578-81.

11. Chang Z, Gallagher RC, Ardey P, Dyckman W, Donahue S, Low HBC. Retrograde flush and cold storage for twenty-two to twenty-five hours' lung preservation with and without PGE $_{1}$. J Heart Lung Transplant 1997;16:658-66.

12. Kitsis RN, Butrick PM, Kass AA, Kaplan ML, Leinwald LA. In: Adolph KW, editor. Methods in molecular genetics. New York: Academic Press; 1993. p. 374-92.

13. Stewart MJ, Plautz GE, Buono LD, et al. Gene transfer in vivo with DNA-liposome complexes: safety and acute toxicity in mice. Hum Gene Ther 1992;3:267-75.

14. San H, Yang ZY, Pompili VJ, et al. Safety and short-term toxicity of a novel cationic lipid formulation for human gene therapy. Hum Gene Ther 1993;4:781-8.

15. Thomas DA, Myers MA, Wichert B, Schreier H, GonzalezRothi RJ. Acute effects of liposome aerosol inhalation on pulmonary function in healthy human volunteers. Chest 1991;99:1268-70.

16. Canonico AE, Plitman JD, Conary JT, Meyric BO, Brigham KL. No lung toxicity after repeated aerosol or intravenous delivery of plasmid-cationic liposome complexes. J Appl Physiol 1994;77:415-9. 